\title{
Correlative Study of Imprint and Crush Cytology with Histopathology in Endobronchial Growths
}

Gulam Qadir Bhat, Showkat Ali Mufti, Thussu S Kumar, Sonaullah Shah, Parviaz Ahmed Koul, Parveen Shah, Ather Hafiz Khan and Rafi Ahmed Jan*

Department of Medicine, Sheri-Kashmir Institute of Medical Sciences, Soura, Srinagar, Kashmir, India

\begin{abstract}
Objective: This study was undertaken to study the correlation between imprint cytology, crush smears and histopathology in endobronchial growths using fiberoptic bronchoscopy.

Methods: The study was conducted in the Department of Internal Medicine and Pathology at Sher-i-Kashmir Institute of Medical Sciences. Eighty-one patients with clinical and radiological evidences of lung lesions were enrolled. From all patients five pieces of tissue were obtained during fiberoptic broncoscopy which revealed an endobronchial growth. From each bit of tissue an imprint and crush smear were prepared by imprinting the tissue on a clean surface of glass slide without compressing the tissue while as crush smear was made by gently crushing the tissue between two glass slides. The tissue specimens were then placed in formaldehyde solution for histological examination. Standard statistical methods were used to analyze the data (chi-square $\left(x^{2}\right)$ analysis; a Fisher's exact test was used to evaluate the data if more than $25 \%$ of the expected values were $<5$ ). The level of significance selected was $\mathrm{P}<0.05$
\end{abstract}

Results: Overall 49 cases $(60.49 \%)$ were diagnosed as malignant and 31 cases $(38.2 \%)$ as benign on histopathology. In one case with active bleed, smears were taken from blood clots and bronchoalveolar lavage was done, both of which revealed malignancy. Forty histopathologically proven malignant cases were positive for malignancy $(81.6 \%)$ on crush smear cytology, while nine cases were not. Imprint smears were positive for malignant cells in 41 cases out of 49 histologically proven malignant cases (83.6\%) and eight cases did not show malignant cells on imprint. The sensitivity, specificity, positive predictive value and negative predictive value of crush smear results were $81.6 \%, 100 \%, 100 \%$ and $77.5 \%$ respectively.

Conclusion: Imprint and crush cytology are rapid, reliable and accurate techniques. The technique can improve the diagnostic accuracy in endobronchial lesions, as it is faster and more cost effective.

Keywords: Imprint and crush; Endobronchial growth; Bronchoscopy; Histopathology

\section{Introduction}

Lung cancer has emerged as the most common form of malignant disease and leading cause of cancer deaths in developed as well as in developing countries [1,2]. In Kashmir, lung cancer is the second most common cancer with high mortality [3]. Smoking remains the leading cause of lung cancer; other risk factors include air pollution, occupational exposures, radiation and genetic factors [4,5]. Prompt and early diagnosis of lung cancer plays a pivotal role in early treatment, planning, management and outcome of patients. Although various investigations like computerized tomography (CT) scan are routinely adopted, imprint cytology has revolutionized and facilitated the diagnosis of tumors [6,7] including those of breast [8], gastrointestinal tract [9], lymph nodes [10] and bone marrow [11]. Imprint cytology can also be used as an intraoperative tool for deciding the extent of surgery a patient has to undergo [12].

The first realization that cancer of the lung could be accurately diagnosed and typed by the microscopic study of expectorated cells is generally attributed to Dudgeon and Patrick [13], Dudgeon and Barret [14]. Other authors have stressed the utility of this technique on malignant and non-malignant lesions. Most of the studies have been confined to lesions in lymph nodes and breast $[8,10]$. In the case series of thyroid lesions reported by Sakai et al. [15] an accuracy of $95.5 \%$ was achieved. Staniszewski et al. $[16,17]$ have done intraoperative cytology during pulmonary surgery with an accuracy of $84 \%$. Pulmonary cytology and histopathology are valuable tools in the diagnosis of lung malignancies. Fibreoptic bronchoscopy was introduced in 1968 as a diagnostic procedure. Since then, apart from sputum, different methods for obtaining satisfactory specimens have become available like bronchial brushings, imprint and crush smears. Although the examination of sputum can provide evidence of malignancy, its sensitivity for accurate diagnosis is only $65 \%[18,19]$ as compared to the specimens collected by fiberoptic bronchoscope which yield a higher positivity rate of $74 \%$, thus revolutionizing the diagnosis of lung cancers. Moreover, specimens obtained by bronchoscopy can be used for cytological examination $[20,21]$. It should, however, be emphasized here that fiberoptic bronchoscopy when combined with pulmonary cytology enhances the sensitivity significantly to $88 \%$ [22]. Okubo et al. [23] showed that touch imprint cytology could be superior to conventional histopathology in the identification of a small proportion of cancer cells against a background of non-malignancy.

*Corresponding author: Rafi Ahmed Jan, Associate Professor, Department of Medicine, SK Institute of Medical Sciences, Soura, Srinagar-190011, Kashmir, India, Tel: +91 194243 2301; Fax: +91 194240 3470; E-mail: rafiahmedjan@gmail.com

Received May 10, 2013; Accepted June 17, 2013; Published June 21, 2013

Citation: Bhat GQ, Mufti SA, Kumar TS, Shah S, Koul PA, et al. (2013) Correlative Study of Imprint and Crush Cytology with Histopathology in Endobronchia Growths. J Cytol Histol 4: 177. doi:10.4172/2157-7099.1000177

Copyright: $(2013$ Bhat GQ, et al. This is an open-access article distributed under the terms of the Creative Commons Attribution License, which permits unrestricted use, distribution, and reproduction in any medium, provided the original author and source are credited. 
Citation: Bhat GQ, Mufti SA, Kumar TS, Shah S, Koul PA, et al. (2013) Correlative Study of Imprint and Crush Cytology with Histopathology in Endobronchial Growths. J Cytol Histol 4: 177. doi:10.4172/2157-7099.1000177

The aim of this study was to evaluate the diagnostic accuracy of imprint and crush smear cytology being faster and cost effective in a low resource setting in the diagnosis of lung cancer. The cytological diagnosis was verified against the histological diagnosis which was considered as the gold standard. The imprint and crush smear technique is simple, cost-effective and appear reliable as other methods such as frozen section. Since the cytological reports are available same day while as histopathology takes 7-8 days, the treatment can be planned earlier.

\section{Material and Methods}

The study was conducted in the Department of Medicine and Pathology at Sheri-Kashmir Institute of Medical Sciences from October 2006 to February 2007. Patients were selected from those referred for bronchoscopy with radiological and clinical evidence of lung lesions to the Department of Medicine. Patients were considered for bronchoscopy who presented with shortness of breath, hemoptysis, cough, chest pain and a radiological evidence of mass on chest radiograph, which was confirmed on a computed tomography scan (CT) with contrast enhancement. A platelet count of $<40,000 /$ cubic millimetre and an oxygen saturation of $>85 \%$ were regarded as contraindications for performing bronchoscopy. An informed consent was routinely obtained from the enrolled patients. Fiberoptic bronchoscopy was done with PENTAX-15 introduced transnasally under $2 \%$ topical xylocaine. The patient was kept on continuous cardiorespiratory monitoring during the procedure.

Eighty-one patients with endobronchial growths seen on bronchoscopy were biopsied with the biopsy forceps of PENTAX-15; no radiological guidance was used. Five to six bits of tissue were obtained from each patient. From each bit of tissue an imprint and crush smear were prepared and rest of the tissue was sent for histopathology. The imprint smear was prepared by imprinting the tissue on clean surface of a glass slide without compressing the tissue while as crush smear was made by gently crushing the tissue between the two glass slides to generate a uniformly spread smear. The smears (imprint and crush) were fixed in $95 \%$ alcohol and later stained by Papanicolaou stain. The tissue specimens were then placed in formaldehyde solution $(10 \%$ formalin) for histological examination.

The smears were read by a pathologist and categorized as negative and positive for malignant cells. Definite differentiation of type of tumor cells was not done based on smears. Two independent pathologists reported the histopathology and cytology and subsequently the results of the study were statistically analyzed.

Standard statistical methods were used to describe and analyze the data. Categorical data consisting of more than two categories were evaluated by chi-square $\left(\chi^{2}\right)$ analysis; a Fisher's exact test was used to evaluate the data if $>25 \%$ of the expected values were $<5$. For calculating sensitivity, specificity and related parameters, methods of Galen and Gambino were used, as follows: sensitivity $=\mathrm{TP} /(\mathrm{TP}+\mathrm{FN}) \mathrm{x} 100$; specificity $=\mathrm{TN} /(\mathrm{TN}+\mathrm{FP}) \mathrm{x} 100$; false positive rate $(\mathrm{FP})=\mathrm{FP} /(\mathrm{FP}+\mathrm{TN})$ $\mathrm{x} 100$; false negative rate $(\mathrm{FN})=\mathrm{FN} /(\mathrm{FN}+\mathrm{TP}) \times 100$; $\mathrm{PV}$ of a positive result $=\mathrm{TP} /(\mathrm{TP}+\mathrm{FP}) \mathrm{x} 100 ; \mathrm{PV}$ of a negative result $=\mathrm{TN} /(\mathrm{TN}+\mathrm{FN})$ $\mathrm{x} 100$; prevalence rate $=(\mathrm{TP}+\mathrm{FN}) /(\mathrm{TP}+\mathrm{TN}+\mathrm{FP}+\mathrm{FN}) \times 100$. The overall diagnostic accuracy is the probability of the patients being correctly identified as true positive and true negative by the cytological test. The level of significance selected was $\mathrm{P}<0.05$.

\section{Results}

Of the 81 patients biopsied, 64 were males and 17 were females with a mean age of 59 years (range 35-76 years). Sixty-six (81.5\%) patients were smokers and in 15 patients (18.5\%) the smoking history was not available. The biopsy specimens were diagnosed as malignant in 49 (60.49\%) and benign in 31 (38.2\%) cases on histopathology. Of these, $40(81.6 \%)$ were positive for malignancy on crush smear cytology while $9(18.4 \%)$ cases were not picked up on the crush smear (Figures 3 and 4). Imprint smears were positive for malignant cells in 41 (83.6\%) of 49 histologically proved malignant cases; 8 cases did not show malignant cells on imprint smear (Figures 1 and 2). The sensitivity, specificity, Positive Predictive Value (PPV) and Negative Predictive Value (NPV) of crush smear results were $81.6 \%, 100 \%, 100 \%$ and $77.5 \%$ respectively (Table 1). As shown in Table 2, the difference between the crush positive and negative in the two groups and Histopathlogical examination(HPE) positive and negative were statistically significant $(\mathrm{p}<0.0005)$.

Imprint cytology showed a better positive yield with sensitivity, specificity, PPV and NPV of $83.6 \%, 100 \%, 100 \%$ and $79.4 \%$ respectively (Table 3). Of the 49 cases of malignancy diagnosed on histopathology,

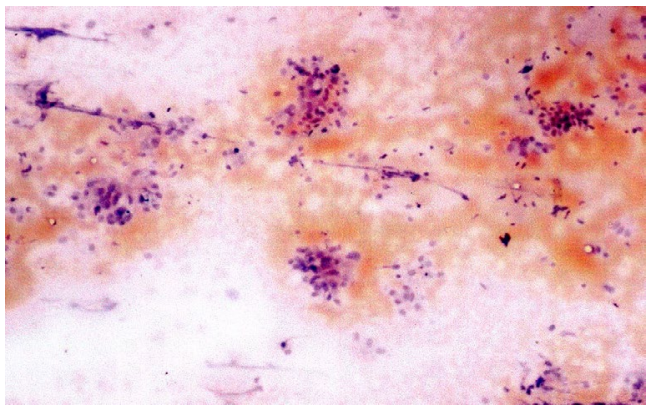

Figure 1: Scanning view of imprint smear of bronchial tissue showing groups of epithelial cells and few inflammatory cells. Pap stain (x-100).

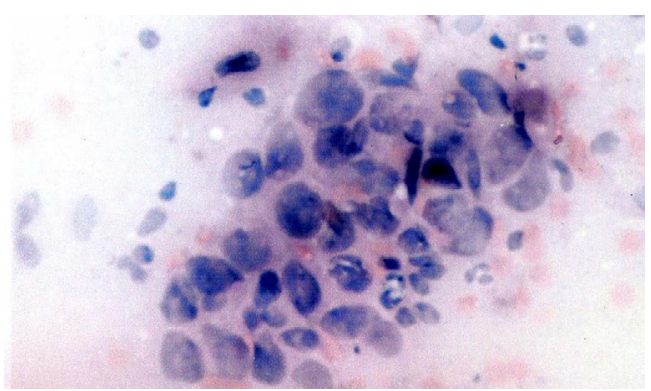

Figure 2: Imprint smear showing groups of malignant cells with marked nuclear pleomorphism Pap stain (x-400).

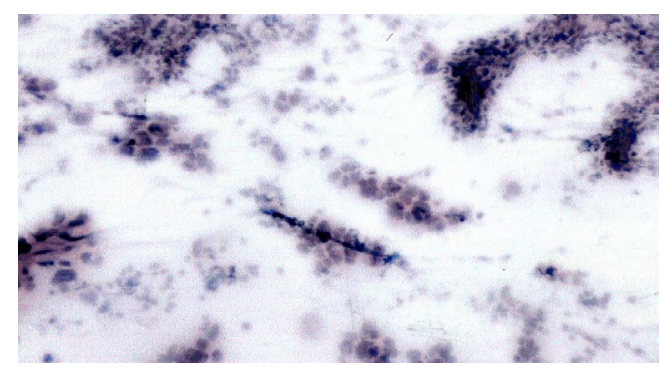

Figure 3: Scanning view of crush smear showing malignant bronchial epithelial cells and few inflammatory cells Pap stain $(x-100)$. 


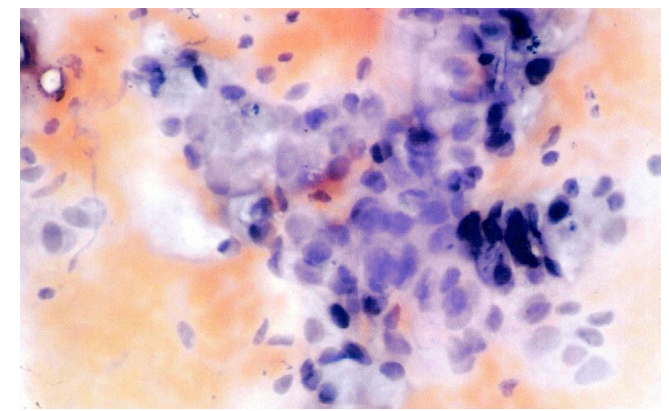

Figure 4: High power view of crush smear showing malignant cells and few inflammatory cells Pap stain (x- 400).

\begin{tabular}{|c|c|c|}
\hline & HPE +ve & HPE -ve (31) \\
\hline Crush +ve & 40 & 0 \\
\hline Crush - ve & 9 & 31 \\
\hline TOTAL & 49 & 31 \\
\hline
\end{tabular}

HPE- Histopathology, +ve-positive, -ve-negative

Sensitivity-

Specificity-

$81.6 \%$

Positive predic

$100 \%$

- dictive value-

$100 \%$

$77.5 \%$

Table 1: Crush smear results in HPE +ve cases.

\begin{tabular}{|c|c|c|}
\hline & $\begin{array}{c}\text { HPE }+v e \\
(n=49)\end{array}$ & $\begin{array}{c}\text { HPE -ve } \\
(n=31)\end{array}$ \\
\hline Crush +ve & $\begin{array}{c}40 \\
81.6 \%)\end{array}$ & 0 \\
\hline Crush -ve & 9 & 31 \\
$(18.4 \%)$ & $(100 \%)$ \\
\hline
\end{tabular}

$P$ value $\left(\right.$ Yates $\left.\chi^{2}\right)=<0.0005$; Yates $\chi^{2}=47.4$

Table 2: Crush smear results in HPE +ve cases.

\begin{tabular}{|c|c|c|}
\hline & HPE +ve (49) & HPE -ve (31) \\
\hline Imprint +ve & 41 & 0 \\
\hline Imprint $-v e$ & 8 & 31 \\
\hline TOTAL & 49 & 31 \\
\hline
\end{tabular}

Table 3: Imprint smear result in HPE +ve cases.

\begin{tabular}{|c|c|c|}
\hline & $\begin{array}{c}\text { HPE }+v e \\
(\mathrm{n}=49)\end{array}$ & $\begin{array}{c}\text { HPE }-\mathrm{ve} \\
(\mathrm{n}=31)\end{array}$ \\
\hline Imprint $+\mathrm{ve}$ & $\begin{array}{c}41 \\
(83.7 \%)\end{array}$ & 0 \\
\hline Imprint $-\mathrm{ve}$ & $\begin{array}{c}8 \\
(16.3 \%)\end{array}$ & 31 \\
$(100 \%)$
\end{tabular}

$P$ value $\left(\right.$ Yates $\left.\chi^{2}\right)=<0.0005$; Yates $\chi^{2}=49.9$

Table 4: Imprint smear result in HPE +ve cases.

17 were small cell carcinoma, 30 were squamous cell carcinoma and 2 were adenocarcinoma. As shown in Table 4 statistical analysis of imprint smear results of HPE positive and negative cases showed a significant difference between the two approaches $(\mathrm{p}=0.0005)$.

\section{Discussion}

Pulmonary cytology and histopathology are valuable tools in the diagnosis of lung malignancies. Fibreoptic bronchoscopy was introduced in 1968 as a diagnostic procedure. Since then, apart from sputum, different methods for obtaining satisfactory specimens have become available like bronchial brushings, imprint and crush smears. Although the examination of sputum can provide evidence of malignancy, its sensitivity for accurate diagnosis is only $65 \%[18,19]$ as compared to the specimens collected by fiberoptic bronchoscope which yield a higher positivity rate of $74 \%$, thus revolutionizing the diagnosis of lung cancers. Moreover, specimens obtained by bronchoscopy can be used for cytological examination [20,21]. It should, however, be emphasized here that fiberoptic bronchoscopy when combined with pulmonary cytology enhances the sensitivity significantly to $88 \%$ [2227].

In this study, we had $81.6 \%-83.6 \%$ sensitivity of crush and imprint cytology, respectively. These results were concordant with the studies conducted by Wolfgang et al. [28] and Paulose et al. [33] who showed sensitivity between $84 \%$ and $89 \%$. We found imprint technique quick and easy to perform, however, there were some false-negative results which could be due to factors like poor smear quality, error in fixation drying artifact, bloody smear, necrotic tissue, fatty or tumor tissue that was fibrosed and/or very scanty tumor cells.

There is a need to find rapid and reliable diagnostic methods, which have high yield of positive and accurate results. Techniques like sputum examination and bronchial washings are inappropriate [25,26] since the site of the specimen cannot be properly examined[27]. Screening is very time-consuming and the number of positive cells in early lesions is relatively low. Degenerative processes have occurred in the body long before the tumor cells can be treated with fixative [28]. The lesion can be visualized by broncoscope, and the location of the specimen can be mapped precisely. Viable cells may be obtained and fixed immediately for detailed cytologic examination. In cytological examinations, the quality of results depends on the skill of the surgeon and the level of cytopathologic expertise [29].

The imprint and crush smear technique is simple, cost-effective and appears as reliable as other methods such as frozen section $[7,30]$. Moreover, several authors have reported that imprint cytology has superior quality to frozen section histopathology, especially for small specimens where there is a sampling error and potential loss of cryo sectioning of lesion tissue, which is necessary for a permanent histopathological diagnosis [31]. The malignant component of a core biopsy specimen may be lost during the processing of permanent section, but imprint smear preserves the malignant cells regardless of the small specimen[32]. The cytological reports are available either the same day or a day after while as histopathology takes 7-8 days. It, therefore, helps a clinician to plan treatment one week earlier.

Imprint and crush cytology is helpful in diagnosing lung malignancy but we did not attempt the differentiation of type of tumor cells based on smear cytology. The superiority of imprint smear cytology over crush smear cytology may be due to fewer artifacts in preparing the smear. Therefore, imprint and crush cytology when used in conjunction, enable early diagnosis of lung cancer. The technique (especially imprint) is quick, sensitive and highly specific method for detecting lung malignancies.

In conclusion, imprint and crush (especially imprint) cytology are easy and reliable methods that can be used to provide quick diagnosis. The imprint cytology technique is quick, reliable, sensitive and highly specific method of detecting lung malignancies. Diagnosis becomes clear at least 7 to 10 days earlier, which helps in planning management faster.

Conflict of interest: none declared. 
Citation: Bhat GQ, Mufti SA, Kumar TS, Shah S, Koul PA, et al. (2013) Correlative Study of Imprint and Crush Cytology with Histopathology in Endobronchial Growths. J Cytol Histol 4: 177. doi:10.4172/2157-7099.1000177

\section{Summary}

\section{Article focus}

The article focuses on the need to incorporate imprint and crush smear cytology in conjunction with histopathology in order to improve the diagnostic yield of bronchoscopy. It also emphasizes the importance of time in planning the management, which ultimately affects the outcome of these patients.

Key messages

- The technique is quite simple and does not need any additional sophisticated equipment.

- The imprint and crush smear techniques are quick, reliable, sensitive and highly specific methods for diagnosing lung malignancy.

Limitations of our study

- On average, the cytology results in this study were available only after approximately 12-18 hours. Availability of imprint cytology results in much shorter intervals (55 minutes) has been reported in literature[34].

- Definite categorization of the lung tumors was not done on smear cytology.

\section{Acknowledgment}

We thank Dr. Shariq Massodi for assistance with statistical analysis, Drs. Henry D. Tazelaar and Saleem Kamili for critical review of the manuscript

\section{References}

1. Cancer research campaign (1992) Factsheet 11. Lung cancer and smoking. Factsheet V. Cancer in the European community. London: CRC.

2. Lung cancer mortality and incidence worldwide in 2008

3. Koul PA, Kaul SK, Sheikh MM, Tasleem RA, Shah A (2010) Lung cancer in the Kashmir valley. Lung India 27: 131-137.

4. Peto R, Lopez AD, Boreham J, Thun M, Heath C Jr (1992) Mortality from tobacco in developed countries: indirect estimation from national vital statistics. Lancet 339: 1268-1278.

5. Smoking and lung cancer (2012) American Cancer Society. Cancer Facts and Figures.

6. Llatjós M, Castellà E, Fraile M, Rull M, Julián FJ, et al. (2002) Intraoperative assessment of sentinel lymph nodes in patients with breast carcinoma: accuracy of rapid imprint cytology compared with definitive histologic workup. Cancer 96: 150-156.

7. Veneti S, loannidou-Mouzaka L, Toufexi H, Xenitides J, Anastasiadis P (1996) Imprint cytology. A rapid, reliable method of diagnosing breast malignancy. Acta Cytol 40: 649-652.

8. Dutta SK, Chattopadhyaya A, Roy S (2001) Evaluation of fine needle aspiration and imprint cytology in the early diagnosis of breast lesions with histopathological correlation. J Indian Med Assoc 99: 421-423.

9. Cubukçu A, Gönüllü NN, Kaçar SO, Alponat A, Paksoy N (2002) Imprint cytology in the endoscopic diagnosis of gastrointestinal malignancies. Hepatogastroenterology 49: 198-200.

10. Agarwal PK, Gosh M, Wahal KM, Mehrotra RM (1977) Study of imprint smears of lymph nodes. Indian J Cancer 14: 157-163.

11. Aboul-Nasr R, Estey EH, Kantarjian HM, Freireich EJ, Andreeff M, et al. (1999) Comparison of touch imprints with aspirate smears for evaluating bone marrow specimens. Am J Clin Pathol 111: 753-758.

12. Lambah PA, McIntyre MA, Chetty U, Dixon JM (2003) Imprint cytology of axillary lymph nodes as an intraoperative diagnostic tool. Eur J Surg Onco 29: $224-228$

13. Dudgeon LS, Patrick CV (1927). A new method for the rapid microscopical diagnosis of tumours: with an account of 200 cases so examined. Br J Surgery 15: $250-261$.

14. Dudgeon LS, Barrett NR (1934) The examination of fresh tissues by the wetfilm method. Br J Surg 22:4-222.

15. Sakai Y, Lauslahti K (1969) Comparison and analysis of the results of cytodiagnosis and frozen sections during operation. Acta Cytol 13: 359-368.

16. Staniszewski A, Marciniak M, Wachacka B, Ortowski TM, Kołodziej J (1996) 55 $\mathrm{P}$-Intraoperative imprint cytology in the diagnosis of lung tumoyrs. European Journal of Cancer, 32: Supplement 1,S11.

17. Shopland DR, Eyre HJ, Pechacek TF (1991) Smoking-attributable cancer mortality in 1991: is lung cancer now the leading cause of death among smokers in the United States? J Natl Cancer Inst 83: 1142-1148.

18. Johnston WW, Bossen EH (1981) Ten years of respiratory cytopathology at Duke University Medical Center. II. The cytopathologic diagnosis of lung cancer during the years 1970 to 1974 , with a comparison between cytopathology and histopathology in the typing of lung cancer. Acta Cytol; 25: 499-505.

19. Sing A, Freudenberg N, Kortsik C, Wertzel H, Klosa B, et al. (1997) Comparison of the sensitivity of sputum and brush cytology in the diagnosis of lung carcinomas. Acta Cytol 41: 399-408.

20. Cortese DA, McDougall JC (1979) Biopsy and brushing of peripheral lung cancer with fluoroscopic guidance. Chest 75: 141-145.

21. Hsu C (1983) Cytologic diagnosis of lung tumors from bronchial brushings of Chinese patients in Hong Kong. Acta Cytol 27: 641-646.

22. Schreiber G, McCrory DC (2003) Performance characteristics of differen modalities for diagnosis of suspected lung cancer: summary of published evidence. Chest 123: 115S-128S

23. Okubo K, Kato T, Hara A, Yoshimi N, Takeda K, et al. (2004) Imprint cytology for detecting metastasis of lung cancer in mediastinal lymph nodes. Ann Thorac Surg 78: 1190-1193.

24. Xing XZ, Gao YN, Zhang DC (2003) [Early diagnosis of lung cancer]. Ai Zheng 22: $221-223$

25. Saltzstein SL, Harrell JH, Cameron T (1977) Brusings, washings, or biopsy? Obtaining maximum value from flexible fiberoptic bronchoscopy in the diagnosis of cancer. Chest 71: 630-632.

26. Suprun H, Pedio G, Ruttner JR (1980) The diagnostic reliability of cytologic typing in primary lung cancer with a review of the literature. Acta Cytol 24 494-500.

27. Bedrossian CW, Rybka DL (1976) Bronchial brushing during fiberoptic bronchoscopy for the cytodiagnosis of lung cancer: comparison with sputum and bronchial washings. Acta Cytol 20: 446-453.

28. Popp W, Rauscher H, Ritschka L (1991) Diagnostic sensitivity of different techniques in the in the diagnosis of lung tumors with the flexible fiberoptic bronchoscope. Comparison of brush biopsy, imprint cytology of forceps biopsy, and histology of forceps biopsy. Cancer 172-5.

29. Laurent F, Latrabe V, Vergier B, Michel P (2000) Percutaneous CT-guided biopsy of the lung: comparison between aspiration and automated cutting needles using a coaxial technique. Cardiovasc Intervent Radiol 23: 266-272.

30. Kontozoglou TE, Cramer HM (1991) The advantages of intraoperative cytology. Analysis of 215 smears and review of the literature. Acta Cytol 35: 154-164.

31. Suen KC, Wood WS, Syed AA, Quenville NF, Clement PB (1978) Role of imprint cytology in intraoperative diagnosis: value and limitations. J Clin Pathol 31: $328-337$

32. Liao WY, Jerng JS, Chen KY, Chang YL, Yang PC, et al. (2004) Value of imprin cytology for ultrasound-guided transthoracic core biopsy. Eur Respir J 24: 905909.

33. Paulose RR, Shee CD, Abdelhadi IA, Khan MK (2004) Accuracy of touch imprint cytology in diagnosing lung cancer. Cytopathology 15: 109-112.

34. Lee TK (1982) The value of imprint cytology in tumor diagnosis: a retrospective study of 522 cases in northern China. Acta Cytol 26: 169-171. 